\title{
Meta-analytic study on the frequency and treatment of oral antral communications
}

\author{
Borja Franco-Carro ${ }^{1}$, Cristina Barona-Dorado ${ }^{2}$, $\mathbf{M}^{\text {a }}$ José-Sandra Martínez-González $^{3}$, Luis-Jesus Rubio- \\ Alonso ${ }^{3}$, Jose-Maria Martínez-González ${ }^{4}$ \\ ${ }^{1}$ Collaborator in the Master's in Oral and Dental Implant Surgery program at Madrid University Hospital \\ ${ }^{2}$ Associate Professor of Oral Surgery at the School of Dentistry, Complutense University of Madrid. Assistant Director of the \\ Master's in Oral and Dental Implant Surgery program at Madrid University Hospital \\ ${ }^{3}$ Professor of the Master's in Oral and Dental Implant Surgery program at Madrid University Hospital \\ ${ }^{4}$ Full Professor of Maxillofacial Surgery at the School of Dentistry, Complutense University of Madrid. Head of the Department \\ of Oral Facial and Implant Surgery at Madrid University Hospital
}

\author{
Correspondence: \\ c) Monte Alto $n^{\circ} 16$ \\ Urb. Los Peñascales \\ 28250 Torrelodones (Madrid) \\ bfranco1979@hotmail.com
}

Received: $13 / 04 / 2010$

Accepted: 27/06/2010
Franco-Carro B, Barona-Dorado C, Martínez-González MJ, Rubio-Alonso LJ, Martínez-González JM. Meta-analytic study on the frequency and treatment of oral antral communications. Med Oral Patol Oral Cir Bucal. 2011 Aug 1;16 (5):e682-7.

http://www.medicinaoral.com/medoralfree01/v16i5/medoralv16i5p682.pdf

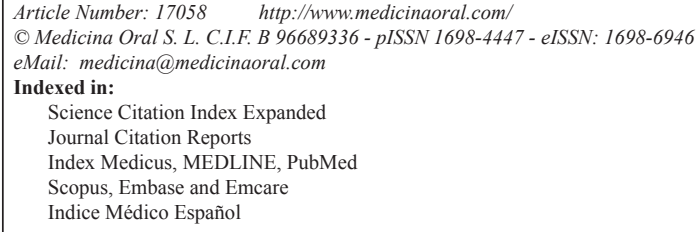

\begin{abstract}
Objective: To determine the optimum surgical treatment for oral antral communications (OAC) and to understand the main post-operative complications.

Study Design: Meta-analytical, observational and retrospective study of 1,072 cases of OAC obtained from a literature review of 15 articles.

Results: OAC occur slightly more often in men and during the fourth decade of life. Its primary etiological factor is dental extraction, most often affecting the third molar. The most common treatment has been the use of Bichat's fat pad grafts, whereas the technique with the highest percentage of complications has been the use of the palatal rotation flap. The most frequent complication has been the fistulization of the OAC.

Conclusions: Early diagnosis of OAC and its treatment within 48 hours of evolution are fundamental in order to properly resolve this pathology. The use of Bichat's fat pad grafts is a simple technique that offers excellent vascularization and results.
\end{abstract}

Key words: Oral-antral, communication, buccosinusal, fistule, treatment.

\section{Introduction}

An oral antral communication (OAC) is a pathological situation in which there is a solution of continuity between the oral cavity and the maxillary sinus as a consequence of the loss of the soft tissues and hard tissues that separate these structures. If the $\mathrm{OAC}$ is maintained open to the oral cavity for more than 48 hours or if there is an infection, chronic inflammation of the sinus membrane and permanent epithelialization of the buccosinusal fistule may occur, thus increasing the risk of sinusitis. In this case, closure of the OAC is combined with a Caldwell-Luc procedure in order to clean the sinus (1). There are multiple surgical techniques described for closing the communications, but the most accepted are the trapezoidal flap, the palatal rota- 
tion flap and the Bichat's fat pad graft $(1,2)$.

$\mathrm{OAC}$ are relatively uncommon surgical complications, although for Rothamel et al. (3), they appear in 13\% of third molar extractions, reflecting the high demand for these extractions in the article published by Leco et al. (4).

They are considered pathologies caused by multiple etiological factors, which include traumatisms, cysts, tumors and other pathological lesions of the sinuses, iatrogenesis and above all, dental extractions (2). Thus, understanding the frequency and how to prevent their appearance, the correct diagnosis, adequate treatment and managing the possible complications that may appear are important both for the dentist as well as the oral surgeon.

On the other hand, due to the existence of numerous studies published on OAC, we find that the results obtained by the different authors vary greatly in terms of the frequency, the etiological factors and the most adequate surgical treatment. Thus, with this meta-analytic study, our objective is to evaluate the different results obtained and to unify opinions so that we are able to prescribe the appropriate treatment in each case in order to resolve this pathological process.

\section{Material and Method}

Study design: meta-analytic, observational, retrospective study in which a literature review has been conducted in the PubMed and Compludoc databases of published literature. Articles published during the period between 1983 and 2008 were reviewed, selecting 15 articles and obtaining a total of 1,072 cases, after establishing the following inclusion criteria: articles with at least one case of OAC in which the cause, treatment used and the complications that appeared following treatment were recorded.

The articles selected were handled using descriptive statistics, in which the variables analyzed were:

Age: We recorded the average age of the patient when the OAC appeared.

Sex: We established whether there was a relationship between the patient's gender and the appearance of such pathology.

Etiological factor: We recorded the cause that led to the $\mathrm{OAC}$ and the articles that also specified it, and we assessed the tooth involved.

Treatment: We evaluated the treatment prescribed.

Complications: We recorded the complications that occurred after the treatment. Pain, inflammation and decreasing of the vestibular depth were not considered as complications, given that they were considered consequences of the surgical treatment performed.

\section{Results}

As far as the sex of the patient is concerned, the pathology was more frequent among men, who accounted for $56.11 \%$ of the cases, versus women, who accounted for $43.89 \%$ of the cases, thus establishing a ratio of 1.28:1.
With regard to the age variable, it is observed that the average age in which a greater frequency of OAC occurs is 42.94 years old, it being shown that the age group of those with the highest tendency toward being affected is between the ages of 40 and 50 years old.

As for the etiological factor, dental extractions represent a significant and most frequent cause (92.63\%), followed by pathological lesions in the sinus (presence of cysts and tumors) and traumatism, which account for $4.47 \%$ and $1.3 \%$ of the cases respectively. Periodontal infections are only the cause in $0.93 \%$ of cases, and other factors account for $0.65 \%$ of the cases.

The third molar, in $41.05 \%$ of cases, followed by the first molar, in $26.74 \%$ of cases, is noted for having a greater involvement of one or more antral teeth and therefore affecting the location of the OAC. In this study, the second molar is involved in $17.7 \%$ of the cases, whereas the second and first premolars are involved in $8.67 \%$ and $4.7 \%$ of cases respectively. OAC due to involvement of the canine tooth only occurs in $1.13 \%$ of the cases.

The predominant treatment (Table 1) in our study has been grafts of Bichat's fat pads in $45.53 \%$ of the cases, whereas $18.75 \%$ of the cases are treated with primary closure of the OAC. The vestibular trapezoidal flap is the technique of choice in $18.2 \%$ of the cases and the palatal rotation flap is used in $12.41 \%$ of the cases. Other treatments are used in $3.35 \%$ of the cases. It is worth noting that in $1.96 \%$ of the cases, the authors do not treat the OAC (Fig. 1).

As far as the complications (Table 1) following the treatment, these included failure to close the OAC in $31.17 \%$ of the cases, followed by partial necrosis of the flap in $18.18 \%$ of the cases. There was a presence of increased granulation tissue in the suture line in $11.68 \%$ of cases and the development of sinusitis in $7.8 \%$ of the cases. Alterations in the sensitivity of the infraorbital nerve occur in $6.5 \%$ of the cases, which is the same percentage recorded for that of the escaping of air and/or liquid. Other complications such as the tooth causing

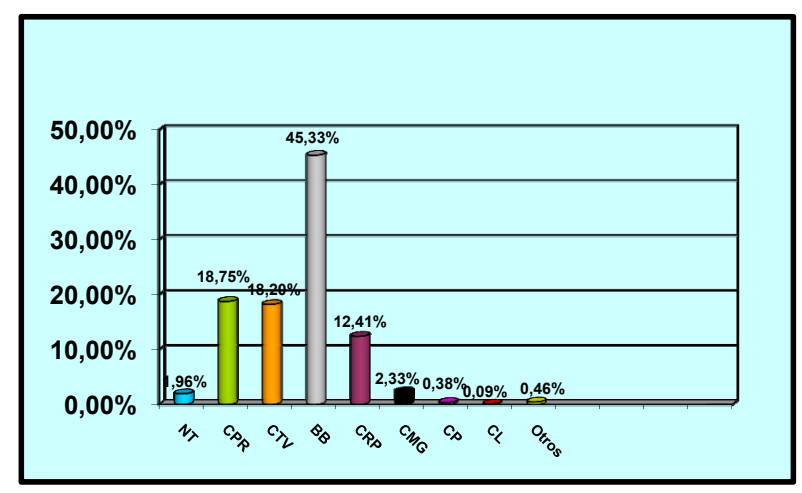

Fig. 1. Treatments performed on OAC. NT: no treatment; CPR: primary closure; CTV: trapezoidal flap; BB: Bichat's fat pad; CRP: palatal rotation flap; CMG: genian mucous flap; CP: bridge flap; CL: lingual flap. 
Table 1. Results from the studies on the treatment and complications of OAC.

\begin{tabular}{|c|c|c|c|}
\hline $\begin{array}{l}\text { AUTHOR } \\
\text { YEAR }\end{array}$ & $\begin{array}{l}\text { No. of } \\
\text { CASES } \\
\text { (n) }\end{array}$ & TREATMENT & COMPLICATIONS \\
\hline $\begin{array}{c}\text { Skoglund (1) } \\
1983\end{array}$ & 85 & $\begin{array}{l}\text { CPR -----57 } \\
\text { CTV-----28 }\end{array}$ & $\begin{array}{c}\text { CPR-----1 F / } 3 \text { SN } \\
\text { CTV-----1 SN }\end{array}$ \\
\hline $\begin{array}{c}\text { Amaratunga (2) } \\
1986 \\
\end{array}$ & 86 & $\begin{array}{l}\text { CTV--- } 44 \\
\text { CRP------42 }\end{array}$ & $\begin{array}{l}\text { CTV-----6 F } \\
\text { CRP-----3 F }\end{array}$ \\
\hline $\begin{array}{c}\text { Stajcic (18) } \\
1992\end{array}$ & 56 & BB-----56 & $\begin{array}{c}\text { H------3 } \\
\text { EG-----7 } \\
\text { NP------2 }\end{array}$ \\
\hline $\begin{array}{c}\text { Adam (19) } \\
1995 \\
\end{array}$ & 300 & BB-----300 & $\mathrm{NC}$ \\
\hline $\begin{array}{c}\text { Hanazawa (9) } \\
1995 \\
\end{array}$ & 14 & BB-----14 & F-----1 \\
\hline $\begin{array}{c}\text { Young-Kyun (17) } \\
1998\end{array}$ & 1 & CL-----1 & $\mathrm{NC}$ \\
\hline $\begin{array}{c}\text { Guven (7) } \\
1998\end{array}$ & 98 & $\begin{array}{c}\text { CTV-----89 } \\
\text { CRP-----5 } \\
\text { CP-----4 }\end{array}$ & $\begin{array}{c}\text { CRP-----2 AI / } 2 \text { EG } \\
\text { CTV-----3 DS }\end{array}$ \\
\hline $\begin{array}{c}\text { Baumann (14) } \\
2000\end{array}$ & 12 & BB-----12 & $\mathrm{NC}$ \\
\hline $\begin{array}{c}\text { Lee }(15) \\
2002\end{array}$ & 21 & CRP-----21 & $\begin{array}{c}\text { F-----5 } \\
\text { NP-----12 }\end{array}$ \\
\hline $\begin{array}{l}\text { Anavi (10) } \\
2003\end{array}$ & 63 & CRP------63 & $\begin{array}{c}\text { EAL---5 } \\
\text { DDC------3 } \\
\text { AC------4 } \\
\text { AI-----3 } \\
\text { HS-----1 } \\
\text { SN-----2 }\end{array}$ \\
\hline $\begin{array}{l}\text { Dolanmaz (11) } \\
2004\end{array}$ & 75 & BB-----75 & $\mathrm{NC}$ \\
\hline $\begin{array}{c}\text { Abuabara (8) } \\
2006\end{array}$ & 101 & $\begin{array}{c}\text { CPR-----61 } \\
\text { BB------28 } \\
\text { CTV-----9 } \\
\text { CRP-----2 } \\
\text { T-----1 }\end{array}$ & $\begin{array}{l}\text { CPR-----4 F } \\
\text { CTV-----1 F } \\
\text { CRP-----1 F }\end{array}$ \\
\hline $\begin{array}{l}\text { Rothamel (3) } \\
2007\end{array}$ & 134 & $\begin{array}{l}\text { NT------21 } \\
\text { CPR------83 } \\
\text { CTV-----25 } \\
\text { Others-----5 }\end{array}$ & CTV-----1 F \\
\hline $\begin{array}{l}\text { De Moraes (20) } \\
2008\end{array}$ & 1 & BB-----1 & $\mathrm{NC}$ \\
\hline $\begin{array}{l}\text { Campos Meirelles } \\
\text { (12) } 2008\end{array}$ & 25 & CMG-----25 & F-----1 \\
\hline
\end{tabular}

CPR: primary closure; CTV: trapezoidal flap; CRP: palatal rotation flap; BB: Bichat's fat pad; CL: 1ingual flap; CP: bridge flap; T: dental transplant; NT: no treatment; CMG: genian mucous flap; F: fistula; SN: sinusitis; H: herniation; EG: excess granulation; NP: partial necrosis; NC: no complications; AI: infraorbital nerve alterations; DS: dehiscence of the suture; EAL: air/liquid escape; DDC: tooth damage due to flap; AC: flap inflammation; HS: herpes simplex. 


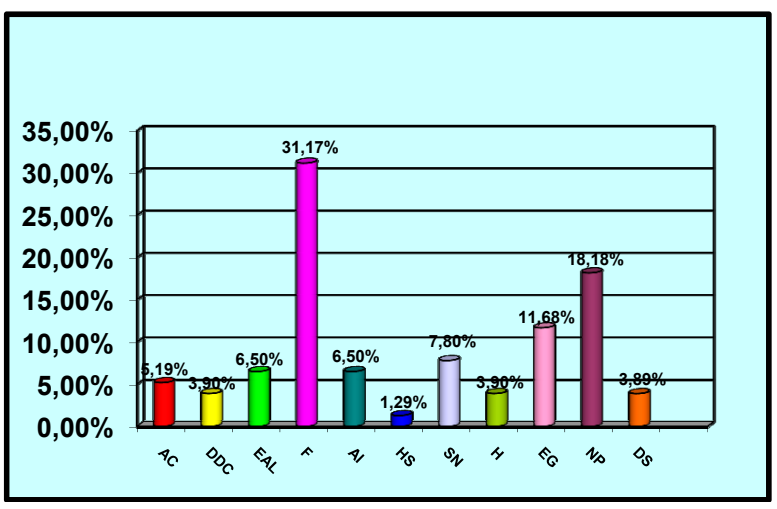

Fig. 2. Complications following treatment of OAC. AC: flap inflammation; DDC: damage from the tooth to the flap; EAL: air/liquid escape; F: fistula; AI: alterations of the infraorbital nerve; HS: herpes simplex; SN: sinusitis; H: herniation; EG: excess granulation; NP: partial necrosis; NC: no complications; DS: dehiscence of the suture.

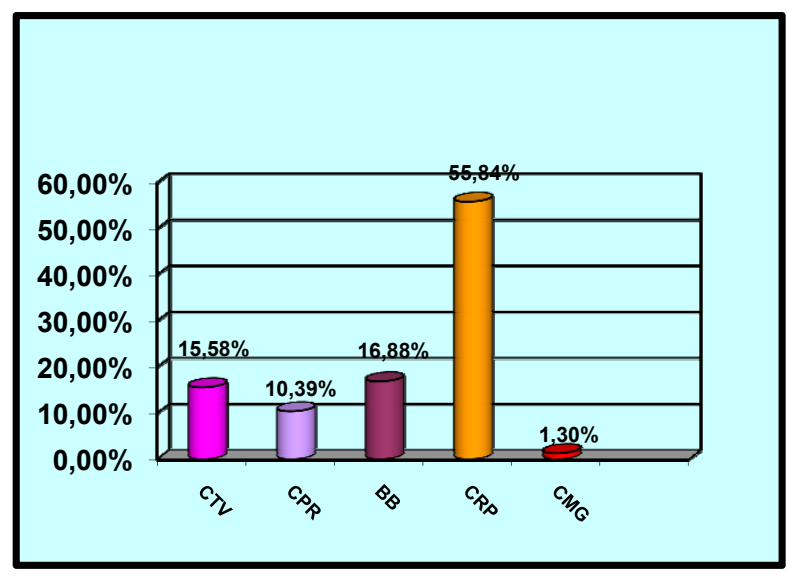

Fig. 3. Complications according to the surgical technique. CTV: trapezoidal flap; CPR: primary closure; B: Bichat's fat pad; CRP: palatal rotation flap; CMG: genian mucous flap.

damage to the flap (3.9\%), inflammation $(5.19 \%)$ and herniation of the flap (3.9\%), infection by herpes simplex $(1.29 \%)$ and dehiscence of the suture $(3.9 \%)$ occur less frequently (Fig. 2).

The complications have also been categorized according to the surgical treatment performed. Thus, the technique that has resulted in the largest number of complications is the palatal rotation flap, accounting for $55.84 \%$ of the cases. In the OAC treated with a Bichat's fat pad graft, there were complications in $16.88 \%$ of the cases, whereas complications were reported in $15.58 \%$ of those patients treated with a vestibular trapezoidal flap. In the communications treated with a primary closure, complications were reported in $10.39 \%$ of the cases, and in $1.3 \%$ of the cases in which the treatment consisted of a mucous flap of the genian region (Fig. 3).
Table 2. Type and number of complications according to the treatment chosen.

\begin{tabular}{|c|c|c|c|c|c|}
\hline \multirow{2}{*}{ COMPLICATIONS } & \multicolumn{5}{|c|}{ TREATMENT } \\
\hline & CTV & CPR & BB & CRP & CMG \\
\hline F & $8(10.39 \%)$ & $5(6.5 \%)$ & $1(1.30 \%)$ & $9(11.68 \%)$ & $1(1.3 \%)$ \\
\hline EAL & & & & $5(6.5 \%)$ & \\
\hline DDC & & & & $3(3.9 \%)$ & \\
\hline AC & & & & $4(5.19 \%)$ & \\
\hline AI & & & & $5(6.5 \%)$ & \\
\hline HS & & & & $1(1.3 \%)$ & \\
\hline SN & $1(1.3 \%)$ & $3(3.9 \%)$ & & $2(2.59 \%)$ & \\
\hline H & & & $3(3.9 \%)$ & & \\
\hline EG & & & $7(9.09 \%)$ & $2(2.59 \%)$ & \\
\hline NP & & & $2(2.59 \%)$ & $12(15.58 \%)$ & \\
\hline DS & $3(3.9 \%)$ & & & & \\
\hline
\end{tabular}

CTV: trapezoidal flap; CPR: primary closure; B: Bichat's fat pad; CRP: palatal rotation flap; CMG: genian mucous flap; F: fistula; EAL: air/liquid escape; DDC: tooth damage due to flap; AC: flap inflammation; AI: infraorbital nerve alterations; HS: herpes simplex; SN: sinusitis; H: herniation; EG: excess granulation; NP: partial necrosis; DS: dehiscence of the suture

Of all the treatment possibilities, the most frequent complication is the fistulization of the OAC, except in the case of the palatal rotation flap, in which partial necrosis is also common. However, with the use of Bichat's fat pad graft, the most frequent complication is the appearance of granulation tissue (Table 2).

\section{Discussion}

OAC are a pathological entity that are often caused by dentists and oral surgeons when performing dental treatments such as surgical extractions, removing cysts and even with iatrogenic approaches such as untimely curretage. They can also be caused by pathological lesions of the maxillary sinus, as well as periodontal infections and traumatisms, as we have mentioned in the results. For these reasons, preventing their appearance 
as well as making the diagnosis and prescribing adequate treatment are very important in order to prevent the formation of an oral antral fistula and the subsequent development of sinusitis.

In regards to gender, our study has found this pathology to be more prevalent among men. This result corresponds to that found in a study by Amaratunga (2), which attributes it to a higher incidence of extractions among males and to the assertion that these extractions are more difficult. However, other authors do not report a difference with respect to gender in the results of their studies (1, 5-7).

Although, all agree that a higher risk of OAC occurs after the third decade of life, which is when the maxillary sinus reaches its complete development (6). With respect to the results of this variable, there is no consensus in the literature reviewed. Del Rey et al. (5) obtained an average of 21 years old, but their study was based only on the appearance of OAC in the extraction of the third molar. Abuabara et al. (8) obtain an average age of 31.2 years old, and justifies this based on the higher incidence of third molar extractions by the dentists. We concur with the findings of Amaratunga (2) which show a higher incidence in the fourth decade of life. According to his study, this is due to the fact that there are a greater number of extractions, whereas other authors attribute it to the pneumatization of the maxillary sinus due to the loss of teeth in the upper maxilla (7). These results contrast with those of Punwutikorn et al. (6), who refer a greater incidence of OAC as of the sixth decade of life. The risk of an OAC occurring in children is minimal due to the size of the maxillary sinus $(2,5-7)$.

As we have been able to verify based on the results obtained in our study, the etiology of OAC may be attributed to traumatisms, periapical surgery, or result as a consequence of alveopalatal fissures, cysts and benign or malignant neoplasms in the sinus mucosa, yet the most significant etiological factor is the extraction of the antral teeth, whether caused by the extraction itself, by the penetration of the roots and teeth to the sinuses, or due to iatrogenic maneuvers by the dentist $(2,3,6-13)$. This is due to the intimate relationship between the maxillary sinus with the tops of the antral teeth, a fine layer of bone measuring 1 to $7 \mathrm{~mm}$ in thickness $(1,8,14)$.

The different authors analyzed in this study do not mention a higher incidence of this pathology on the right side in comparison with the left side. As regards the location of the OAC depending on the tooth involved, there are various opinions in the literature reviewed. According to Güven et al. (7), the main cause of the occurrence of a communication is due to extraction of the second premolar, and its results differ from those of the study published by Von Bonsdorff in 1925 on 84 skulls, in which he verified that the second molar was the most closely connected with the floor of the maxillary sinus.
However, there are various authors who assert that it is the extraction of the first molar that most often leads to this pathology $(2,6,15)$. In contrast, our results show that it is the region of the third molar that is most frequently involved in the OAC, which coincides with the results obtained by Skoglund et al. (1) and Abuabara et al. (8), with the later asserting that it is due to the high number of third molar extractions performed.

As far as the surgical treatment of OAC, there is no consensus among the various authors on which treatment to use, although they do agree that if the patient presents a previous acute or chronic sinusitis, the treatment of this infection must be administered prior to the surgical closure of the communication, because if not, the oral antral communication will reappear. What the majority of the authors do agree on is that if the oral antral communication persists after 48-72 hours of evolution, it forms a fistula and becomes permanent, with the consequent risk of sinusitis $(1,2)$. Nevertheless, there is no consensus of criteria and there is a certain debate among the authors. Some contend that perforations with a diameter of less than $5 \mathrm{~mm}$ may be closed spontaneously without requiring surgical treatment, provided there is no prior infection and a stable blood clot forms $(13,16)$, whereas others such as Güven (7), Abuabara et al. (8) and Hanazawa et al. (9) maintain that if the size of the oral antral communication is $2 \mathrm{~mm}$ or greater, it must be surgically closed.

Multiple techniques have been described for the treatment of $\mathrm{OAC}$, including the injection of human fibrin glue (Tissucol ${ }^{\circledR}$ ) in the communication itself; use of beta-tricalcium (RootRéplica ${ }^{\circledR}$ ) and guided tissue regeneration (GTR) have also been proposed as an option using alloplastic materials. Another treatment alternative published with good results is to perform auto-transplantation of the third molar, followed by its subsequent extraction $(8,17-19)$.

Lingual flaps are another possibility due to the excellent vascularization that they offer, but the post-operative recovery process is complicated for the patient, given that such flaps may require maxillomandibular fixation as well as a second surgery in order to set the flap back into place (20). The use of buccal mucosal flaps in the genian region has also been described, but it was observed that they cause partial obliteration of the labial gingival area, with its prosthetic consequences, as well as stress on the flap due to the movement of the lips and cheek, thus requiring a secondary vestibuloplasty (12). Currently, the techniques most often used for the treatment of OAC are vestibular and palatal flaps (10). In the results of his study, Amaratunga (2) does not report any differences between the vestibular trapezoidal flap and the palatal rotation flap; and like Skoglund et al. (1), he attributes more importance to the treatment of the sinus infection versus that of the surgical technique used. 
Similarly, Güven (7) asserts that the vestibular trapezoidal flap is a simple technique that is well-tolerated and offers good results, and that the loss of vestibular depth is temporary and disappears after 8 weeks. Therefore, he reserves the palatal rotation flap for cases in which there is little vestibular depth, and uses the bridge flap for edentulous patients who have reduced vestibular depth due to alveolar resorption.

If the size of the oral antral communication is small (3-5 $\mathrm{mm}$ ), primary closure using sutures is a good alternative for Abuabara et al. (8), whereas for communications that are larger than $5 \mathrm{~mm}$, he recommends the use of Bichat's fat pad graft, because it is a very vascularized structure. Although the vestibular trapezoidal flap is the simplest technique, it offers poor blood irrigation and causes a decrease in the vestibular depth. In addition, the palatal rotation flap achieves good blood irrigation, but the post-operative recovery process is painful for the patient and requires good adeptness on the part of the attending doctor. In order to avoid these limitations, some authors demand that the palatal island flap be used (16), whereas other authors do not find limitations with the palatal rotation flap and describe it as the treatment of choice $(10,15)$.

In our study, the palatal rotation flap is the technique in which the greatest number of complications is reported, which namely include the fistulization of the OAC and partial necrosis of the flap. The same is reported in the article published by Lee ey al. (15), whereas in the studies published by Güven (7) and Anavi et al. (10), none of these complications are described. This circumstance may be due to the fact that the OAC treated by Lee et al. (15) with a palatal rotation flap are in the region of the third molars, and according to Abuabara et al. (8), this type of flap is not indicated for communications in this area because the blood irrigation is compromised in the rotation of the flap due to the anatomic location of the previous palatal hole.

However, in OAC treated with a Bichat's fat pad graft, only one fistulazation of the communication occurred (9).

As our results show, what is certain is that it appears evident that in the literature reviewed, there are various authors who recommend using a Bichat's fat pad graft due to the excellent results obtained in their studies, the advantages it offers and the very few postoperative complications described $(11,14,21-23)$, possibly attributed to the excellent vascularization via branches of the maxillary artery, superficial temporal artery and small ramifications of the facial artery, according to Hanazawa et al. (9), who assert that it is a technique that may be applied to many cases, that it is easy to use, has a low rate of failure if it is performed properly, and produces minimal discomfort for the patient during the postoperative recovery process.

\section{References with links to Crossref - DOI}

\section{References}

1. Skoglund LA, Pedersen SS, Holst E. Surgical management of 85 perforations to the maxillary sinus. Int J Oral Surg. 1983;12:1-5.

2. Amaratunga NA. Oro-antral fistulae- a study of clinical, radiological and treatment aspects. Br J Oral Maxillofac Surg. 1986;24:433-7. 3. Rothamel D, Wahl G, d'Hoedt B, Nentwig GH, Schwarz F, Becker $\mathrm{J}$. Incidence and predictive factors for perforation of the maxillary antrum in operations to remove upper wisdom teeth: prospective multicentre study. Br J Oral Maxillofac Surg. 2007;45:387-91.

4. Leco Berrocal MI, Martínez González JM, Donado Rodríguez M. Social demand in ambulatory oral surgery. Experience in the Master of Oral Surgery of Madrid Complutense University (Spain). Med Oral Patol Oral Cir Bucal. 2008;13:E39-42.

5. Del Rey-Santamaría M, Valmaseda Castellón E, Berini Aytés L, Gay Escoda C. Incidence of oral sinus communications in 389 upper thirmolar extraction. Med Oral Patol Oral Cir Bucal. 2006;11:E334-8. 6. Punwutikorn J, Waikakul A, Pairuchvej V. Clinically significant oroantral communications- a study of incidence and site. Int J Oral Maxillofac Surg. 1994;23:19-21.

7. Güven O. A clinical study on oroantral fistulae. J Craniomaxillofac Surg. 1998;26:267-71.

8. Abuabara A, Cortez AL, Passeri LA, de Moraes M, Moreira RW. Evaluation of different treatments for oroantral/oronasal communications: experience of 112 cases. Int J Oral Maxillofac Surg. 2006;35:155-8.

9. Hanazawa Y, Itoh K, Mabashi T, Sato K. Closure of oroantral communications using a pedicled buccal fat pad graft. J Oral Maxillofac Surg. 1995;53:771-5.

10. Anavi Y, Gal G, Silfen R, Calderon S. Palatal rotation-advancement flap for delayed repair of oroantral fistula: a retrospective evaluation of 63 cases. Oral Surg Oral Med Oral Pathol Oral Radiol Endod. 2003;96:527-34.

11. Dolanmaz D, Tuz H, Bayraktar S, Metin M, Erdem E, Baykul T. Use of pedicled buccal fat pad in the closure of oroantral communication: analysis of 75 cases. Quintessence Int. 2004;35:241-6.

12. Meirelles RC, Neves-Pinto RM. Oroantral fistula and genian mucosal flap: a review of 25 cases. Braz J Otorhinolaryngol. 2008;74:85-90.

13. Awang MN. Closure of oroantral fistula. Int J Oral Maxillofac Surg. 1988;17:110-5.

14. Baumann A, Ewers R. Application of the buccal fat pad in oral reconstruction. J Oral Maxillofac Surg. 2000;58:389-92.

15. Lee JJ, Kok SH, Chang HH, Yang PJ, Hahn LJ, Kuo YS. Repair of oroantral communications in the third molar region by random palatal flap. Int J Oral Maxillofac Surg. 2002;31:677-80.

16. James RB. Surgical closure of large oroantral fistulas using a palatal island flap. J Oral Surg. 1980;38:591-5.

17. Stajcić Z, Todorović LJ, Petrović V. Tissucol in closure of oroantral communication. A pilot study. Int J Oral Surg. 1985;14:444-6.

18. Thoma K, Pajarola GF, Grätz KW, Schmidlin PR. Bioabsorbable root analogue for closure of oroantral communications after tooth extraction: a prospective case-cohort study. Oral Surg Oral Med Oral Pathol Oral Radiol Endod. 2006;101:558-64.

19. Waldrop TC, Semba SE. Closure of oroantral communication using guided tissue regeneration and an absorbable gelatin membrane. J Periodontol. 1993;64:1061-6.

20. Kim YK, Yeo HH, Kim SG. Use of the tongue flap for intraoral reconstruction: a report of 16 cases. J Oral Maxillofac Surg. 1998;56:716-9.

21. Stajcić Z. The buccal fat pad in the closure of oro-antral communications: a study of 56 cases. J Craniomaxillofac Surg. 1992;20:193-7.

22. Adam P, Mercier J, Billet J, Huet P. The Bichat ball. The surgical value of oro-sinus communications. Rev Stomatol Chir Maxillofac. 1995;96:379-84.

23. De Moraes EJ. Closure of oroantral communication with buccal fat pad flap in zygomatic implant surgery: a case report. Int J Oral Maxillofac Implants. 2008;23:143-6. 